\title{
Genotoxic potential of dental bulk-fill resin composites
}

Tauböck, Tobias T ; Marovic, Danijela ; Zeljezic, Davor ; Steingruber, Andrea D ; Attin, Thomas ; Tarle, Zrinka

\begin{abstract}
OBJECTIVE: To investigate both genotoxicity and hardening of bulk-fill composite materials applied in 4-mm layer thickness and photo-activated for different exposure times. METHODS: Three flowable bulk-fill materials and one conventional flowable composite were filled in molds (height: $4 \mathrm{~mm}$ ) and irradiated for 20 or $30 \mathrm{~s}$. The top $(0 \mathrm{~mm})$ and bottom $(4 \mathrm{~mm})$ specimen surface were mechanically scraped, and eluates $(0.01 \mathrm{~g}$ composite in $1.5 \mathrm{ml}$ RPMI 1640 cell culture media) prepared for each material, surface level and irradiation time. Genotoxicity was assessed in human leukocytes using both the alkaline comet assay and cytokinesis-blocked micronucleus assay, and Knoop hardness $(\mathrm{KHN})$ was measured at the top and bottom specimen surface $(\mathrm{n}=8)$. RESULTS: At both irradiation times, none of the bulk-fill composites significantly affected comet assay parameters used in primary DNA damage assessment or induced significant formation of any of the scored chromatin abnormalities (number of micronuclei, nuclear buds, nucleoplasmic bridges), whether eluates were obtained from the top or bottom surface. Furthermore, no decrease in KHN from the top to the bottom surface of the bulk-fill materials was observed. On the other hand, the conventional composite irradiated for 20s showed at 4-mm depth a significant increase in the percentage of DNA that migrated in the tail and a significant increase in the number of nuclear buds, as well as a significant decrease in KHN relative to the top surface. SIGNIFICANCE: Bulk-fill resin composites, in contrast to conventional composite, applied in 4-mm thickness and photo-activated for at least 20 s do not induce relevant genotoxic effects or mechanical instability.
\end{abstract}

DOI: https://doi.org/10.1016/j.dental.2017.04.011

Posted at the Zurich Open Repository and Archive, University of Zurich

ZORA URL: https://doi.org/10.5167/uzh-145015

Journal Article

Accepted Version

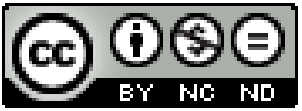

The following work is licensed under a Creative Commons: Attribution-NonCommercial-NoDerivatives 4.0 International (CC BY-NC-ND 4.0) License.

Originally published at:

Tauböck, Tobias T; Marovic, Danijela; Zeljezic, Davor; Steingruber, Andrea D; Attin, Thomas; Tarle, Zrinka (2017). Genotoxic potential of dental bulk-fill resin composites. Dental Materials, 33(7):788-795.

DOI: https://doi.org/10.1016/j.dental.2017.04.011 


\section{Genotoxic potential of dental bulk-fill resin composites}

Tobias T. Tauböck ${ }^{a, *}$, Danijela Marovic ${ }^{b}$, Davor Zeljezic ${ }^{c}$, Andrea D. Steingruber $^{a}$, Thomas Attin ${ }^{\mathrm{a}}$, Zrinka Tarle

${ }^{a}$ Department of Preventive Dentistry, Periodontology and Cariology,

Center for Dental Medicine, University of Zurich, Zurich, Switzerland

${ }^{\mathrm{b}}$ Department of Endodontics and Restorative Dentistry,

School of Dental Medicine, University of Zagreb, Zagreb, Croatia

${ }^{\mathrm{c}}$ Division for Mutagenesis, Institute for Medical Research and Occupational Health, Zagreb, Croatia

\section{Short title:}

Genotoxicity of bulk-fill composites

\section{Keywords:}

Resin composite, bulk-fill, biocompatibility, genotoxicity, microhardness

\section{${ }^{*}$ Corresponding author:}

PD Dr. Tobias T. Tauböck

Department of Preventive Dentistry, Periodontology and Cariology

Center for Dental Medicine, University of Zurich

Plattenstrasse 11, CH-8032 Zurich, Switzerland

Tel: +41446343448, Fax: +41446344308

E-mail: tobias.tauboeck@zzm.uzh.ch 


\section{ABSTRACT}

Objectives: To investigate both genotoxicity and hardening of bulk-fill composite materials applied in 4-mm layer thickness and photo-activated for different exposure times.

Methods: Three flowable bulk-fill materials and one conventional flowable composite were filled in molds (height: $4 \mathrm{~mm}$ ) and irradiated for 20 or 30 s. The top $(0 \mathrm{~mm})$ and bottom $(4 \mathrm{~mm})$ specimen surface were mechanically scraped, and eluates $(0.01 \mathrm{~g}$ composite in $1.5 \mathrm{ml}$ RPMI 1640 cell culture media) prepared for each material, surface level and irradiation time. Genotoxicity was assessed in human leukocytes using both the alkaline comet assay and cytokinesis-blocked micronucleus assay, and Knoop hardness (KHN) was measured at the top and bottom specimen surface $(n=8)$.

Results: At both irradiation times, none of the bulk-fill composites significantly affected comet assay parameters used in primary DNA damage assessment or induced significant formation of any of the scored chromatin abnormalities (number of micronuclei, nuclear buds, nucleoplasmic bridges), whether eluates were obtained from the top or bottom surface. Furthermore, no decrease in $\mathrm{KHN}$ from the top to the bottom surface of the bulk-fill materials was observed. On the other hand, the conventional composite irradiated for 20 s showed at 4-mm depth a significant increase in the percentage of DNA that migrated in the tail and a significant increase in the number of nuclear buds, as well as a significant decrease in KHN relative to the top surface.

Significance: Bulk-fill resin composites, in contrast to conventional composite, applied in 4-mm thickness and photo-activated for at least 20 s do not induce relevant genotoxic effects or mechanical instability. 


\section{Introduction}

Light-activated resin composites are nowadays the most frequently used direct restorative materials in dentistry [1]. Despite their widespread use and reliable evidence of their clinical long-term success [2], concerns exist about possible intrinsic toxicity of resin-based composite materials $[3,4]$.

The effects of masticatory forces and chemical degradation can cause composite restorations to release harmful substances into the pulp or saliva, which may thereby pass into the bloodstream. Nearly all components of dental resin composites can be eluted in the oral cavity, but the elution of resin monomers is of particular interest due to their potential cytotoxic and genotoxic effects [5-7]. It has been shown that the release of residual unreacted monomers inversely correlates with the degree of monomer to polymer conversion [8]. In order to increase the degree of conversion of resin-based composite materials, low molecular weight monomers, such as 2-hydroxyethyl methacrylate (HEMA) and triethylene glycol dimethacrylate (TEGDMA) are usually utilized as diluent monomers [9,10]. However, these monomers also reduce the levels of glutathione, a natural radical scavenger that protects cell structures from damage caused by reactive oxygen species. These effects can cause oxidative stress and DNA strand breakage [11,12]. In addition to HEMA and TEGDMA, bisphenol-A-glycidyldimethacrylate (Bis-GMA), an often-used base monomer in composite materials, has also demonstrated dose-dependent genotoxicity by increasing the number of micronuclei and DNA strand breaks $[13,14]$.

In recent years, a new category of composite materials, so-called bulk-fill resin composites, have been developed in order to simplify and expedite the restorative process. According to manufacturers' claims, these materials can be properly photo-polymerized even when applied in thick layers up to $4-5 \mathrm{~mm}$, and maintain low polymerization stress at the same time. To this end, novel proprietary resins, unique fillers, special polymerization modulators, and optimized photoinitiators were formulated. While studies substantiated reduced polymerization stress formation [15-17] and increased curing depths of bulk-fill composite materials compared with conventional resin composites $[18,19]$, a decline in 
micromechanical properties of bulk-fill resin composites at 4-mm depth and beyond has also been reported [20,21]. At such composite layer thickness, curing light penetration might be hindered, thus reducing the degree of monomer to polymer conversion and increasing the release of unconverted monomers, which might compromise biocompatibility. Indeed, a recent study revealed for some bulk-fill resin composites cytotoxic effects not compatible with the ISO cutoff of $70 \%$ cell viability when the materials were applied in 4-mm layer thickness and photo-activated for $20 \mathrm{~s}$ [22]. The genotoxic potential of bulk-fill composite materials, as well as its dependence on light exposure time, is as yet unknown. Due to their higher resin content and more persistent mass leaching compared with conventional hybrid composite materials [23], low-viscosity flowable (bulk-fill) composites might be particularly relevant for genotoxicity testing.

The comet assay was previously established as an initial indicator of general, non-specific DNA damage/genotoxicity [24], enabling detection of a wide range of primary DNA damage such as single and double strand breaks, alkylation, and oxidatively damaged DNA bases. To quantify DNA damage by means of the comet assay, the parameters tail length $(\mu \mathrm{m})$ and tail intensity (\% DNA) are most frequently used. Tail length determines the length of DNA migration and is directly related to DNA fragment size and the extent of DNA damage, whereas tail intensity denotes the number of DNA fragments, which directly indicates the proportion of the genome affected by the damage [25].

In recent years, the micronucleus has been accepted as the predominant biomarker in genotoxicity evaluation [26]. The micronucleus is formed in cells exposed to a genotoxic agent as the consequence of induced DNA strand breaks that will result in chromosome aberration, or damage to mitotic spindle proteins, which leads to the lag of chromosomes and unsegregation. In addition to the micronucleus, other aberrant chromatin structures such as nuclear buds and nucleoplasmic bridges should be considered when evaluating genotoxic potential, because they represent visualization of chromosomal re-arrangements and premature telomere shortening [27]. 
The aim of the present study was to investigate the in vitro genotoxicity of low-viscosity bulk-fill resin composites applied in 4-mm layer thickness and photo-activated for different exposure times. In addition, microhardness, as an indirect measure of the degree of conversion $[28,29]$, was assessed at both the top and bottom surface of the composite specimens in order to allow an estimation of the extent of resin polymerization.

\section{Materials and methods}

\subsection{Specimen preparation}

Three flowable bulk-fill composite materials [SDR (Dentsply DeTrey, Konstanz, Germany), Venus Bulk Fill (Heraeus Kulzer, Hanau, Germany), x-tra base (VOCO, Cuxhaven, Germany)] and one conventional flowable resin composite [Tetric EvoFlow (Ivoclar Vivadent, Schaan, Liechtenstein)] were used. Details of the test materials are presented in Table 1. The composite materials were filled into cylindrical Teflon molds (height: $4 \mathrm{~mm}$, diameter: $10 \mathrm{~mm}$ ) placed on a glass plate and Mylar strip. The applied composite materials were covered with another Mylar strip and $1 \mathrm{~mm}$ thick glass plate, and pressed to the height of the mold. Photo-activation was performed for either 20 or $30 \mathrm{~s}$ with a LED light-curing unit (Bluephase G2; Ivoclar Vivadent) by placing the curing light tip in contact with the glass plate covering the top surface of the specimen. Output irradiance of the light source $\left(1170 \mathrm{~mW} / \mathrm{cm}^{2}\right)$ was measured by using a calibrated FieldMaxll-TO power meter and PM2 thermopile sensor (Coherent, Santa Clara, CA, USA), and verified periodically during the experiments. After photo-activation, the composite specimens were stored for $24 \mathrm{~h}$ in the dark at $37^{\circ} \mathrm{C}$. 


\subsection{Genotoxicity testing}

\subsubsection{Preparation of eluates}

Both the top and bottom surface of the composite specimens were used to prepare eluates of each material tested. Each of these surfaces was scraped separately, ensuring that the entire surface was uniformly removed. Scraping was done mechanically by using a stainless steel dental scaler. Hence, two eluates were prepared from each material for a specific curing time applied: one from the top surface layer and the other from the 4-mm deep bottom surface layer. Samples were pulverized manually with an agate mortar [30]. To obtain the eluate, $0.01 \mathrm{~g}$ of pulverized scrapings of a distinct layer was incubated in $1.5 \mathrm{ml}$ of RPMI 1640 cell culture media (Sigma-Aldrich, Taufkirchen, Germany) at $37^{\circ} \mathrm{C}$ and $5 \% \mathrm{CO}_{2}$ for $48 \mathrm{~h}$. Amount of $0.01 \mathrm{~g}$ corresponds to the quantity of scrapings obtained when $1 \mathrm{~mm}$ of the top or bottom surface of the specimens was removed. The quantity of medium was empirically determined. The eluates were centrifuged (Biofuge Pico, Heraeus Instruments, Hanau, Germany) at $2000 \mathrm{~g}$ for $10 \mathrm{~min}$ to remove the scrapings, and the supernatant thus obtained was used for whole blood culture treatment.

\subsubsection{Blood sampling}

With written informed consent, blood from a 39-year old male non-smoker volunteer with no medical record of chronic or acute adverse health conditions was collected in heparinized vacutainers (BD Vacutainer Plus, Becton Dickinson, Oxford, UK) through antecubital venipuncture. To overcome possible inter-individual differences in response to the treatment, a single-donor sampling approach was applied. The study was approved by the ethical committee of the Institute for Medical Research and Occupational Health, Zagreb.

\subsubsection{Alkaline comet assay}

Whole blood cultures were prepared by introducing $0.6 \mathrm{ml}$ of blood into $4.5 \mathrm{ml}$ of RPMI 1640 cell culture media supplemented with $1 \mathrm{ml}$ of $15 \%$ foetal calf serum (Sigma-Aldrich) and $1 \%$ 
antibiotics (penicillin and streptomycin; Gibco, Paisley, UK), and treated with $1.5 \mathrm{ml}$ of eluate for $4 \mathrm{~h}$ at $37^{\circ} \mathrm{C}$ and $5 \% \mathrm{CO}_{2}$. Both negative and positive controls were included in the study, and the former control cultures remained untreated. Positive control slides were prepared by treating the slides made from negative control cultures with $50 \mu \mathrm{l}$ of $1 \mathrm{mM} \mathrm{H}_{2} \mathrm{O}_{2}$ for 10 min on ice. After the treatment, the cultures were centrifuged at $300 \mathrm{~g}$ for $5 \mathrm{~min}$, the supernatant was removed and the pellet re-suspended. Alkaline comet assay was performed according to Singh et al. [31], and all chemicals required were purchased from Sigma-Aldrich. Seven microliters of cell suspension was mixed with $100 \mu$ of $0.5 \%$ low melting point agarose (LMPA) at $37^{\circ} \mathrm{C}$, layered on $1 \%$ normal melting-point agarose (NMPA)-precoated microscope slides, and placed at $4^{\circ} \mathrm{C}$ for $10 \mathrm{~min}$. These slides were immersed in chilled lysis buffer $(2.5 \mathrm{M} \mathrm{NaCl}, 0.1 \mathrm{M}$ EDTA, $10 \mathrm{mM}$ Tris- $\mathrm{HCl}, 1 \%$ Triton $\mathrm{X}-100, \mathrm{pH} 10)$ and incubated at $4^{\circ} \mathrm{C}$ for $1 \mathrm{~h}$. Denaturation was performed by using an alkaline solution $(0.3 \mathrm{M} \mathrm{NaOH}, 1 \mathrm{mM}$ EDTA, $\mathrm{pH}>13)$ for $20 \mathrm{~min}$ and followed by electrophoresis in an alkaline solution $(0.3 \mathrm{M}$ $\mathrm{NaOH}, 1 \mathrm{mM}$ EDTA, $\mathrm{pH}>13)$ at $0.7 \mathrm{~V} / \mathrm{cm}$ and $300 \mathrm{~mA}$ for $20 \mathrm{~min}$. The slides were neutralized in three changes of buffer $(0.4 \mathrm{M}$ Tris- $\mathrm{HCl}, \mathrm{pH} 7.5)$ at 5-min intervals, stained with ethidium bromide $(20 \mathrm{~g} / \mathrm{ml})$, and analyzed under $25 x$ objective magnification with an epifluorescence microscope (BX 51 Olympus, Tokyo, Japan) using the Comet Assay IV analysis system (Perceptive Instruments, Bury St. Edmunds, UK). For each material layer and light-curing duration, a hundred comets were measured on duplicate slides, and comet tail length $(\mu \mathrm{m})$ and intensity (percentage of DNA in the comet tail) were recorded.

\subsubsection{Cytokinesis-blocked micronucleus assay}

Whole blood cultures were produced by introducing $0.6 \mathrm{ml}$ of blood into $4.5 \mathrm{ml}$ of RPMI 1640 cell culture media supplemented with $1 \mathrm{ml}$ of $15 \%$ foetal calf serum (Sigma-Aldrich) and $1 \%$ antibiotics (penicillin and streptomycin; Gibco), and treated with $1.5 \mathrm{ml}$ of eluate during the entire cultivation period. Lymphocytes were stimulated by $1 \%$ phytohaemagglutinin (Remel, Dartford, UK), and incubated for $72 \mathrm{~h}$ at $37^{\circ} \mathrm{C}$. Cultivation and slide preparation were performed according to a standard protocol [32]. Again, negative and positive controls were 
included. The negative control cultures were supplemented by an additional $1.5 \mathrm{ml}$ of RPMI 1640 media, whereas positive controls were treated with ethyl methanesulfonate (EMS; Sigma-Aldrich) at a final concentration of $200 \mu \mathrm{g} / \mathrm{ml}$. Cytokinesis was arrested by adding cytochalasin B (Sigma-Aldrich) at a final concentration of $6 \mu \mathrm{g} / \mathrm{ml}$ to the culture after $44 \mathrm{~h}$ of incubation. The cells were centrifuged, washed in saline solution $(0.9 \% \mathrm{NaCl}$, Sigma-Aldrich) and fixed with $3: 1(\mathrm{v} / \mathrm{v})$ methanol/acetic acid solution. The slides were stained with $5 \%$ Giemsa (Merck, Darmstadt, Germany). One thousand binucleated cells with well-preserved cytoplasm were scored on each duplicate slide per treatment to determine the total number of micronuclei in binucleated lymphocytes, nuclear buds, and nucleoplasmic bridges, and the scoring criteria described by Fenech [32] were applied.

\subsection{Determination of microhardness}

Knoop hardness $(\mathrm{KHN})$ was measured at the top and bottom specimen surface using a digital microhardness tester (model no. 1600-6106; Buehler, Lake Bluff, IL, USA). For each specimen $(n=8)$, four indentations were performed at each surface under a load of $100 \mathrm{~g}$ and a dwell time of $20 \mathrm{~s}$, and the average of the four readings was calculated (per surface of each specimen).

\subsection{Statistical analysis}

To normalize distribution, results of the comet assay tail length and tail intensity were transformed by applying a log transformation [33]. Data of both comet assay parameters (tail length, tail intensity) were analyzed using one-way ANOVA and Tukey's post-hoc test. The chi-square-test was applied in order to test for differences in the number of micronuclei, nuclear buds and nucleoplasmic bridges. Within each composite material separately, differences in KHN between the top surface and bottom surface for each irradiation time were analyzed using paired t-tests, whereas differences in KHN achieved with different irradiation times (20 vs. $30 \mathrm{~s}$ ) at each composite layer were tested using unpaired Student's t-tests. The $\alpha$-type error was set at $5 \%$ for all statistical analyses $(p<0.05)$. 


\section{Results}

\subsection{Alkaline comet assay}

The results of the comet assay are presented in Table 2. For none of the tested composite materials significant differences in tail length values were observed in comparison with the untreated control group, irrespective of irradiation time and layer depth. Furthermore, no significant differences in tail intensity values were detected between the bulk-fill resin composites and the untreated control at any layer depth, whether irradiation was performed for 20 or $30 \mathrm{~s}$. In case of the conventional flowable composite material Tetric EvoFlow irradiated for $20 \mathrm{~s}$, a significant increase in the percentage of DNA that migrated in the tail was observed at a layer depth of $4 \mathrm{~mm}$ as compared with the negative control $(3.6 \pm 2.9 \mathrm{vs}$. $1.4 \pm 1.7)$. Furthermore, within Tetric EvoFlow, the percentage of DNA migrating in the tail was significantly higher at 4-mm depth compared with that at the top surface when irradiation was performed for $20 \mathrm{~s}(3.6 \pm 2.9$ vs. $0.9 \pm 0.9)$. Irradiation time (20 vs. $30 \mathrm{~s})$ did not affect the level of primary DNA damage with regard to the eluate obtained from a given layer depth of a given material.

\subsection{Cytokinesis-blocked micronucleus assay}

The results of the micronucleus assay are detailed in Table 3. None of the evaluated bulk-fill composite materials induced statistically significant formation of any of the scored chromatin abnormalities (number of micronuclei, nuclear buds, nucleoplasmic bridges), irrespective of irradiation time and layer depth. However, at 4-mm depth, the conventional flowable composite material Tetric EvoFlow irradiated for $20 \mathrm{~s}$ significantly increased the number of nuclear buds as compared with the negative control.

\subsection{Microhardness}

Knoop hardness (KHN) values of all experimental groups are presented in Table 4. The conventional flowable composite Tetric EvoFlow attained significantly lower $\mathrm{KHN}$ at the 
bottom surface than at the top surface whether irradiation was performed for 20 or $30 \mathrm{~s}$. No significant differences between top and bottom KHN were observed within the bulk-fill materials x-tra base and Venus Bulk Fill, irrespective of irradiation time. The bulk-fill material SDR even reached significantly higher $\mathrm{KHN}$ at 4-mm depth (bottom surface) than at the top surface with both irradiation times. Increasing the irradiation time from 20 to 30 s significantly increased bottom KHN of Tetric EvoFlow, but had no effect on either top or bottom KHN of the tested bulk-fill resin composites.

\section{Discussion}

Bulk-fill resin composites are gaining in popularity among clinicians, since they enable the placement of thick composite layers, and therefore allow a simplified and less time-consuming restorative procedure. While their physico-mechanical properties, handling characteristics and wear performance have been extensively tested [34-39], scientific data on the biocompatibility of bulk-fill composite materials are very scarce [22]. The present study is the first that investigated potential genotoxic effects emanating from resin-based bulk-fill materials. It revealed that none of the tested bulk-fill resin composites affected comet assay parameters used in primary DNA damage assessment, or induced formation of any of the scored chromatin abnormalities in the micronucleus assay.

The finding that eluates obtained from both the top and bottom composite surface of the tested bulk-fill materials did not induce genotoxic effects might be explained by an adequate extent of polymerization of the bulk-fill resin composites, even when applied in 4-mm thickness. In the present study, microhardness was used as an indirect measure of the extent of polymerization of a specific composite material $[40,41]$, due to its proven correlation with the degree of conversion $[28,29]$. Our results revealed no decrease in microhardness from the top to the bottom surface of the tested bulk-fill resin composites, thus indicating adequate monomer to polymer conversion through the whole depth of the $4 \mathrm{~mm}$ thick specimens. Alrahlah et al. [35], using Vickers hardness profiles, determined that the depth of 
cure of various bulk-fill composite materials ranged from 4.14 to $5.03 \mathrm{~mm}$, which confirms the claims of the manufacturers for the tested materials. Zorzin et al. [42] reported degree of conversion values of $71 \%, 65 \%$, and $61 \%$ at the top surface, and $72 \%, 73 \%$, and $62 \%$ at the bottom (4 mm) surface of SDR, Venus Bulk Fill, and $x$-tra base, respectively. The materials thus attained clinically acceptable levels of monomer conversion of $>55 \%$ [43]. In accordance with the current results, other studies using Raman or infrared spectroscopy also confirmed 4-mm depth of cure of flowable bulk-fill resin composites [17,44]. Moreover, in line with Czasch \& Ilie [45], increasing irradiation time beyond $20 \mathrm{~s}$ did not further improve their degree of hardness. Reliable photo-polymerization of $4 \mathrm{~mm}$ thick layers of bulk-fill resin composites at relatively short irradiation times might be explained by the high translucency of these materials [36]. The bulk-fill materials used in the present study contain large filler particles with up to $5-10 \mu \mathrm{m}$ filler size (Table 1). At a given filler amount, increasing the filler size reduces the filler-matrix interface area, which decreases light scattering. This allows more photons to penetrate the material, and, consequently, increased depths of cure can be attained

Mean microhardness values of the tested flowable bulk-fill resin composites were in the following order: $x$-tra base $>$ SDR $>$ Venus Bulk Fill, which is in agreement with other studies [46,47], and follows the order of the filler loading of the materials. Indeed, strong positive correlations between surface hardness and filler content have been previously reported $[37,47,48]$. According to a material database published by llie et al. [46], hardness values of the flowable bulk-fill materials SDR and Venus Bulk Fill are below the mean value established for the category of conventional flowable composites, while $\mathrm{x}$-tra base reaches hardness values comparable to those of regular microhybrid composites. In the present study, lower hardness values were measured compared to those reported by llie et al. [46], which can be attributed to the fact that, in order to avoid any heat production, the resin-rich surface layer was not removed by polishing prior to hardness testing $[21,49]$.

Alshali et al. [50], using liquid chromatography/mass spectroscopy, revealed generally similar resin matrix compositions of bulk-fill composites and conventional materials, with the 
exception of SDR, which is based on a modified UDMA resin system. Furthermore, despite increased increment thickness of bulk-fill composites, monomer elution from these materials has been shown to be comparable to that of conventional composites, with the rate of elution being dependent on monomer molecular weight [51]. Beside the degree of conversion [8,52], the cross-link density of the polymer network affects the extent of monomer elution [53]. While highly cross-linked polymers are more resistant to solvent uptake and swelling due to reduced free volume in the network, linear polymers provide more space and pathways for diffusion of solvent molecules within the structure [54,55]. Recent studies observed a high degree of chemical softening for SDR, with about $75 \%$ reduction of surface hardness after ethanol storage, indicating poor cross-link density of the polymer $[37,47]$. In addition, SDR showed the highest amount of TEGDMA elution within the group of bulk-fill materials $[51,56]$. However, the less cross-linked polymer structure of SDR apparently did not compromise genotoxicity parameters in the present study.

In case of the conventional flowable resin composite Tetric EvoFlow, other than for the bulk-fill composite materials, a significant increase in the percentage of DNA that migrated in the tail, and thus a higher level of primary DNA damage, was observed compared with the untreated control at a layer depth of $4 \mathrm{~mm}$ when irradiation was performed for $20 \mathrm{~s}$. The result was further substantiated by the observed significant increase of nuclear buds for the same experimental condition, which probably reflects increased repair processes due to the high level of DNA damage induced by the treatment [57]. Again, this finding reflects the results of the microhardness evaluation, which indicate a decrease in hardening, and thus a decrease in the extent of polymerization from the top to the bottom surface of the $4 \mathrm{~mm}$ thick composite specimens. Previous studies also showed a decrease in monomer conversion of conventional resin composites when placed in increment thickness exceeding $2 \mathrm{~mm}[21,42]$. Bearing in mind that conventional composite materials are indicated for use only in layers of max. 2-mm thickness, and thus not in a 4-mm bulk-fill technique, this result was not surprising. Testing the conventional flowable composite material at 4-mm depth enabled us to assess genotoxic effects of inadequately polymerized material. Tetric 
EvoFlow contains a higher amount of resin matrix than the other materials tested (Table 1), which may have contributed to the higher tail intensity. Kleinsasser et al. [13] revealed that Bis-GMA, the main ingredient of the resin matrix of Tetric EvoFlow, increased DNA migration in a comet assay that was tested on human lymphocytes, with Bis-GMA being more genotoxic than HEMA, TEGDMA or UDMA. According to our findings, applying Tetric EvoFlow at increased layer thickness of $4 \mathrm{~mm}$ should thus be omitted, not only due to mechanical instability of the material, but also due to its genotoxic potential.

Micronuclei originate from primary lesions that act as topoisomerase II poisons by inducing double strand DNA breaks. Through error-prone repair, these DNA strand breaks may result in formation of acentric fragments that will form micronuclei [58]. Since no significant increase in both of the measured biomarkers of primary DNA damage was observed, it is reasonable that treatment with the eluates of the bulk-fill materials tested under the conditions applied did not affect the level of micronuclei in treated lymphocytes. The eluate obtained from Tetric EvoFlow at a layer depth of $4 \mathrm{~mm}$ after $20 \mathrm{~s}$ of irradiation significantly increased both the percentage of DNA that migrated into the tail (Table 2) and the frequency of nuclear buds (Table 3). Considering the fact that nuclear buds may be formed by the elimination of DNA repair complexes [57], the results of the micronucleus assay confirm those obtained by the alkaline comet assay.

\section{Conclusion}

Within the experimental conditions of the present in vitro study, it is concluded that placement of the tested bulk-fill composite materials, but not the conventional flowable resin composite, in 4-mm layer thickness can be recommended in terms of both mechanical stability and biocompatibility. An irradiation time of $20 \mathrm{~s}$ (at an irradiance of $\approx 1200 \mathrm{~mW} / \mathrm{cm}^{2}$ ) might suffice for the bulk-fill resin composites under investigation to not induce relevant genotoxic effects. Increasing the irradiation time beyond $20 \mathrm{~s}$ does not further improve the mechanical properties or biocompatibility of the tested bulk-fill composite materials. 


\section{Acknowledgments}

This research was supported by the authors' institutions and the Croatian Science Foundation (Project 08/31). Parts of this paper (KHN determination, KHN data) are based on the master thesis of undergraduate student A.D. Steingruber [59], University of Zurich, supervised by T.T. Tauböck and T. Attin. 


\section{References}

[1] Stein PS, Sullivan J, Haubenreich JE, Osborne PB. Composite resin in medicine and dentistry. J Long Term Eff Med Implants 2005;15:641-54.

[2] Beck F, Lettner S, Graf A, Bitriol B, Dumitrescu N, Bauer P, et al. Survival of direct resin restorations in posterior teeth within a 19-year period (1996-2015): A metaanalysis of prospective studies. Dent Mater 2015;31:958-85.

[3] Kleinsasser NH, Schmid K, Sassen AW, Harreus UA, Staudenmaier R, Folwaczny M, et al. Cytotoxic and genotoxic effects of resin monomers in human salivary gland tissue and lymphocytes as assessed by the single cell microgel electrophoresis (Comet) assay. Biomaterials 2006;27:1762-70.

[4] Wegehaupt FJ, Tauböck TT, Attin T, Belibasakis GN. Influence of light-curing mode on the cytotoxicity of resin-based surface sealants. BMC Oral Health 2014;14:48.

[5] Blasiak J, Synowiec E, Tarnawska J, Czarny P, Poplawski T, Reiter RJ. Dental methacrylates may exert genotoxic effects via the oxidative induction of DNA double strand breaks and the inhibition of their repair. Mol Biol Rep 2012;39:7487-96.

[6] Visalli G, Baluce B, La Maestra S, Micale RT, Cingano L, De Flora S, et al. Genotoxic damage in the oral mucosa cells of subjects carrying restorative dental fillings. Arch Toxicol 2013;87:179-87.

[7] Pettini F, Savino M, Corsalini M, Cantore S, Ballini A. Cytogenetic genotoxic investigation in peripheral blood lymphocytes of subjects with dental composite restorative filling materials. J Biol Regul Homeost Agents 2015;29:229-33.

[8] Ferracane JL. Elution of leachable components from composites. J Oral Rehabil $1994 ; 21: 441-52$

[9] Peutzfeldt A. Resin composites in dentistry: the monomer systems. Eur J Oral Sci 1997;105:97-116.

[10] Chen MH. Update on dental nanocomposites. J Dent Res 2010;89:549-60. 
[11] Lee DH, Lim BS, Lee YK, Ahn SJ, Yang HC. Involvement of oxidative stress in mutagenicity and apoptosis caused by dental resin monomers in cell cultures. Dent Mater 2006;22:1086-92.

[12] Schweikl H, Spagnuolo G, Schmalz G. Genetic and cellular toxicology of dental resin monomers. J Dent Res 2006;85:870-7.

[13] Kleinsasser NH, Wallner BC, Harreus UA, Kleinjung T, Folwaczny M, Hickel R, et al. Genotoxicity and cytotoxicity of dental materials in human lymphocytes as assessed by the single cell microgel electrophoresis (comet) assay. J Dent 2004;32:229-34.

[14] Li YC, Kuan YH, Huang FM, Chang YC. The role of DNA damage and caspase activation in cytotoxicity and genotoxicity of macrophages induced by bisphenol-Aglycidyldimethacrylate. Int Endod J 2012;45:499-507.

[15] Tauböck TT, Feilzer AJ, Buchalla W, Kleverlaan CJ, Krejci I, Attin T. Effect of modulated photo-activation on polymerization shrinkage behavior of dental restorative resin composites. Eur J Oral Sci 2014;122:293-302.

[16] El-Damanhoury H, Platt J. Polymerization shrinkage stress kinetics and related properties of bulk-fill resin composites. Oper Dent 2014;39:374-82.

[17] Marovic D, Tauböck TT, Attin T, Panduric V, Tarle Z. Monomer conversion and shrinkage force kinetics of low-viscosity bulk-fill resin composites. Acta Odontol Scand 2015;73:474-80.

[18] Flury S, Hayoz S, Peutzfeldt A, Husler J, Lussi A. Depth of cure of resin composites: is the ISO 4049 method suitable for bulk fill materials? Dent Mater 2012;28:521-8.

[19] Benetti AR, Havndrup-Pedersen C, Honore D, Pedersen MK, Pallesen U. Bulk-fill resin composites: polymerization contraction, depth of cure, and gap formation. Oper Dent 2015;40:190-200.

[20] Jang JH, Park SH, Hwang IN. Polymerization shrinkage and depth of cure of bulk-fill resin composites and highly filled flowable resin. Oper Dent 2015;40:172-80. 
[21] Tarle Z, Attin T, Marovic D, Andermatt L, Ristic M, Tauböck TT. Influence of irradiation time on subsurface degree of conversion and microhardness of high-viscosity bulk-fill resin composites. Clin Oral Investig 2015;19:831-40.

[22] Toh WS, Yap A, Lim SY. In Vitro Biocompatibility of Contemporary Bulk-fill Composites. Oper Dent 2015;40:644-52.

[23] Wataha JC, Lockwood PE, Bouillaguet S, Noda M. In vitro biological response to core and flowable dental restorative materials. Dent Mater 2003;19:25-31.

[24] Tice RR, Agurell E, Anderson D, Burlinson B, Hartmann A, Kobayashi H, et al. Single cell gel/comet assay: guidelines for in vitro and in vivo genetic toxicology testing. Environ Mol Mutagen 2000;35:206-21.

[25] Shaposhnikov SA, Salenko VB, Brunborg G, Nygren J, Collins AR. Single-cell gel electrophoresis (the comet assay): loops or fragments? Electrophoresis 2008;29:300512.

[26] Cavallo D, Ursini CL, Rondinone B, lavicoli S. Evaluation of a suitable DNA damage biomarker for human biomonitoring of exposed workers. Environ Mol Mutagen 2009;50:781-90.

[27] Fenech M. Cytokinesis-block micronucleus cytome assay. Nat Protoc 2007;2:1084104.

[28] Rueggeberg FA, Craig RG. Correlation of parameters used to estimate monomer conversion in a light-cured composite. J Dent Res 1988;67:932-7.

[29] Price RB, Whalen JM, Price TB, Felix CM, Fahey J. The effect of specimen temperature on the polymerization of a resin-composite. Dent Mater 2011;27:983-9.

[30] Morikawa A. Sample preparation for X-ray fluorescence analysis II. Pulverizing methods of powder samples. Rigaku J 2014;30:23-7.

[31] Singh NP, McCoy MT, Tice RR, Schneider EL. A simple technique for quantitation of low levels of DNA damage in individual cells. Exp Cell Res 1988;175:184-91.

[32] Fenech M. Cytokinesis-block micronucleus assay evolves into a "cytome" assay of chromosomal instability, mitotic dysfunction and cell death. Mutat Res 2006;600:58-66. 
[33] Lovell DP, Omori T. Statistical issues in the use of the comet assay. Mutagenesis 2008;23:171-82.

[34] Petrovic LM, Zorica DM, Stojanac IL, Krstonosic VS, Hadnadjev MS, Atanackovic TM. A model of the viscoelastic behavior of flowable resin composites prior to setting. Dent Mater 2013;29:929-34.

[35] Alrahlah A, Silikas N, Watts DC. Post-cure depth of cure of bulk fill dental resincomposites. Dent Mater 2014;30:149-54.

[36] Bucuta S, Ilie N. Light transmittance and micro-mechanical properties of bulk fill vs. conventional resin based composites. Clin Oral Investig 2014;18:1991-2000.

[37] Leprince JG, Palin WM, Vanacker J, Sabbagh J, Devaux J, Leloup G. Physicomechanical characteristics of commercially available bulk-fill composites. J Dent $2014 ; 42: 993-1000$.

[38] Barkmeier WW, Takamizawa T, Erickson RL, Tsujimoto A, Latta M, Miyazaki M. Localized and generalized simulated wear of resin composites. Oper Dent 2015;40:322-35.

[39] Tauböck TT, Tarle Z, Marovic D, Attin T. Pre-heating of high-viscosity bulk-fill resin composites: Effects on shrinkage force and monomer conversion. J Dent $2015 ; 43: 1358-64$

[40] Tauböck TT, Oberlin H, Buchalla W, Roos M, Attin T. Comparing the effectiveness of self-curing and light curing in polymerization of dual-cured core buildup materials. J Am Dent Assoc 2011;142:950-6.

[41] Tauböck TT, Buchalla W, Hiltebrand U, Roos M, Krejci I, Attin T. Influence of the interaction of light- and self-polymerization on subsurface hardening of a dual-cured core build-up resin composite. Acta Odontol Scand 2011;69:41-7.

[42] Zorzin J, Maier E, Harre S, Fey T, Belli R, Lohbauer U, et al. Bulk-fill resin composites: Polymerization properties and extended light curing. Dent Mater 2015;31:293-301.

[43] Alshali RZ, Silikas N, Satterthwaite JD. Degree of conversion of bulk-fill compared to conventional resin-composites at two time intervals. Dent Mater 2013;29:e213-7. 
[44] Par M, Gamulin O, Marovic D, Klaric E, Tarle Z. Raman spectroscopic assessment of degree of conversion of bulk-fill resin composites-changes at 24 hours post cure. Oper Dent 2015;40:E92-101.

[45] Czasch P, Ilie N. In vitro comparison of mechanical properties and degree of cure of bulk fill composites. Clin Oral Investig 2013;17:227-35.

[46] Ilie N, Bucuta S, Draenert M. Bulk-fill resin-based composites: an in vitro assessment of their mechanical performance. Oper Dent 2013;38:618-25.

[47] Alshali RZ, Salim NA, Satterthwaite JD, Silikas N. Post-irradiation hardness development, chemical softening, and thermal stability of bulk-fill and conventional resin-composites. J Dent 2015;43:209-18.

[48] Chung $\mathrm{KH}$, Greener EH. Correlation between degree of conversion, filler concentration and mechanical properties of posterior composite resins. J Oral Rehabil 1990;17:48794.

[49] Gordan VV, Patel SB, Barrett AA, Shen C. Effect of surface finishing and storage media on bi-axial flexure strength and microhardness of resin-based composite. Oper Dent 2003;28:560-7.

[50] Alshali RZ, Salim NA, Sung R, Satterthwaite JD, Silikas N. Qualitative and quantitative characterization of monomers of uncured bulk-fill and conventional resin-composites using liquid chromatography/mass spectrometry. Dent Mater 2015;31:711-20.

[51] Alshali RZ, Salim NA, Sung R, Satterthwaite JD, Silikas N. Analysis of long-term monomer elution from bulk-fill and conventional resin-composites using high performance liquid chromatography. Dent Mater 2015;31:1587-98.

[52] Durner J, Obermaier J, Draenert M, llie N. Correlation of the degree of conversion with the amount of elutable substances in nano-hybrid dental composites. Dent Mater 2012;28:1146-53.

[53] Benetti AR, Asmussen E, Munksgaard EC, Dewaele M, Peutzfeldt A, Leloup G, et al. Softening and elution of monomers in ethanol. Dent Mater 2009;25:1007-13. 
[54] Ferracane JL. Hygroscopic and hydrolytic effects in dental polymer networks. Dent Mater 2006;22:211-22.

[55] Cavalcante LM, Schneider LF, Silikas N, Watts DC. Surface integrity of solventchallenged ormocer-matrix composite. Dent Mater 2011;27:173-9.

[56] Cebe MA, Cebe F, Cengiz MF, Cetin AR, Arpag OF, Ozturk B. Elution of monomer from different bulk fill dental composite resins. Dent Mater 2015;31:e141-9.

[57] Lindberg HK, Wang X, Jarventaus H, Falck GC, Norppa H, Fenech M. Origin of nuclear buds and micronuclei in normal and folate-deprived human lymphocytes. Mutat Res $2007 ; 617: 33-45$.

[58] Mladinic M, Kopjar N, Milic M, Dasovic AB, Huzak M, Zeljezic D. Genomic instability in a healthy elderly population: a pilot study of possible cytogenetic markers related to ageing. Mutagenesis 2010;25:455-62.

[59] Steingruber AD. Polymerisationsverhalten von fliessfähigen Bulk-Fill-Kompositen in dicken Schichtstärken. Master thesis, Zürich 2015. 
Table 1 - Manufacturers' information about the resin composite materials used in the study.

\begin{tabular}{|c|c|c|c|c|}
\hline $\begin{array}{l}\text { Material } \\
\text { (Lot no., shade) }\end{array}$ & Composition & $\begin{array}{l}\text { Filler size } \\
\qquad(\mu \mathrm{m})\end{array}$ & $\begin{array}{c}\text { Filler content } \\
\text { (wt\%/vol\%) }\end{array}$ & Manufacturer \\
\hline $\begin{array}{l}\text { SDR } \\
(01272, U)\end{array}$ & $\begin{array}{l}\text { Resin: Modified UDMA, } \\
\text { Bis-EMA, TEGDMA } \\
\text { Filler: Ba-Al-F-B-Si-glass, } \\
\text { Sr-Al-F-Si-glass, } \mathrm{TiO}_{2}\end{array}$ & $\begin{array}{c}0.02-10 \\
\text { (mean: } 4.2 \text { ) }\end{array}$ & $68 / 45$ & $\begin{array}{l}\text { Dentsply DeTrey, } \\
\text { Konstanz, } \\
\text { Germany }\end{array}$ \\
\hline $\begin{array}{l}\text { Venus Bulk Fill } \\
(010032 S, U)\end{array}$ & $\begin{array}{l}\text { Resin: UDMA, Bis-EMA } \\
\text { Filler: Ba-Al-F-Si-glass, } \mathrm{YbF}_{3} \text {, } \\
\quad \mathrm{SiO}_{2}\end{array}$ & $\begin{array}{c}0.02-5 \\
\text { (mean: 0.73) }\end{array}$ & $65 / 38$ & $\begin{array}{l}\text { Heraeus Kulzer, } \\
\text { Hanau, } \\
\text { Germany }\end{array}$ \\
\hline $\begin{array}{l}\text { x-tra base } \\
(1307486, U)\end{array}$ & $\begin{array}{l}\text { Resin: Bis-EMA, aliphatic } \\
\text { dimethacrylates } \\
\text { Filler: Ba-Al-Si-glass, } \mathrm{YbF}_{3} \text {, } \\
\text { fumed } \mathrm{SiO}_{2}\end{array}$ & $\begin{array}{c}0.05-7 \\
\text { (mean: } 3.5 \text { ) }\end{array}$ & $75 / 60$ & $\begin{array}{l}\text { Voco, } \\
\text { Cuxhaven, } \\
\text { Germany }\end{array}$ \\
\hline $\begin{array}{l}\text { Tetric EvoFlow } \\
\text { (R70839, A3) }\end{array}$ & $\begin{array}{l}\text { Resin: Bis-GMA, UDMA, } \\
\text { DDDMA } \\
\text { Filler: Ba-glass, } \mathrm{YbF}_{3}, \mathrm{SiO}_{2} \text {, } \\
\text { mixed oxide, prepolymer }\end{array}$ & $\begin{array}{c}0.04-3 \\
\text { (mean: 0.55) }\end{array}$ & $62 / N P$ & $\begin{array}{l}\text { Ivoclar Vivadent, } \\
\text { Schaan, } \\
\text { Liechtenstein }\end{array}$ \\
\hline
\end{tabular}

Bis-GMA: Bisphenol-A-glycidyldimethacrylate; Bis-EMA: Ethoxylated bisphenol-A-dimethacrylate; DDDMA: Decandiol dimethacrylate; UDMA: Urethane dimethacrylate; TEGDMA: Triethylene glycol dimethacrylate; U: Universal; NP: Information not provided. 
Table 2 - Results of alkaline comet assay for leukocytes treated with 48-h eluates of different composite materials in respect of irradiation time and layer depth.

\begin{tabular}{|c|c|c|c|c|c|c|c|c|}
\hline \multirow[t]{2}{*}{ Material } & \multirow[t]{2}{*}{$\begin{array}{l}\text { Irradiation } \\
\text { time (s) }\end{array}$} & \multirow[t]{2}{*}{$\begin{array}{l}\text { Depth } \\
(\mathrm{mm})\end{array}$} & \multicolumn{3}{|c|}{$\begin{array}{l}\text { Tail length } \\
\quad(\mu \mathrm{m})\end{array}$} & \multicolumn{3}{|c|}{$\begin{array}{c}\text { Tail intensity } \\
\text { (\% of DNA in tail) }\end{array}$} \\
\hline & & & Mean & Median & $\overline{S D}$ & Mean & Median & SD \\
\hline \multirow[t]{4}{*}{ SDR } & 20 & 0 & 19.2 & 19.6 & 1.6 & 1.8 & 2.2 & 2.2 \\
\hline & & 4 & 19.4 & 19.6 & 1.2 & 2.2 & 2.1 & 2.4 \\
\hline & 30 & 0 & 19.4 & 20.0 & 2.6 & 2.0 & 1.2 & 2.7 \\
\hline & & 4 & 19.9 & 19.6 & 2.2 & 2.6 & 1.2 & 3.4 \\
\hline Venus & 20 & 0 & 19.4 & 19.2 & 2.0 & 2.8 & 1.9 & 3.4 \\
\hline \multirow[t]{3}{*}{ Bulk Fill } & & 4 & 19.5 & 19.6 & 1.8 & 2.6 & 2.8 & 2.6 \\
\hline & 30 & 0 & 19.3 & 19.2 & 1.9 & 2.5 & 1.3 & 3.3 \\
\hline & & 4 & 19.3 & 18.7 & 2.9 & 2.8 & 1.7 & 3.6 \\
\hline \multirow[t]{4}{*}{ x-tra base } & 20 & 0 & 19.1 & 19.2 & 2.1 & 1.8 & 1.3 & 2.2 \\
\hline & & 4 & 19.5 & 19.2 & 2.4 & 2.4 & 1.2 & 3.4 \\
\hline & 30 & 0 & 20.4 & 20.0 & 2.9 & 2.3 & 1.4 & 2.7 \\
\hline & & 4 & 18.4 & 18.3 & 2.0 & 2.9 & 1.3 & 3.8 \\
\hline Tetric & 20 & 0 & 17.6 & 16.6 & 5.0 & 0.9 & 2.0 & 0.9 \\
\hline \multirow[t]{3}{*}{ EvoFlow } & & 4 & 20.0 & 19.1 & 5.4 & $3.6^{1,2}$ & 4.3 & 2.9 \\
\hline & 30 & 0 & 18.6 & 18.3 & 5.2 & 0.8 & 0.7 & 0.7 \\
\hline & & 4 & 18.2 & 18.0 & 3.9 & 1.8 & 1.5 & 1.5 \\
\hline \multicolumn{3}{|c|}{ Negative control group (untreated) } & 19.2 & 19.2 & 1.6 & 1.4 & 1.0 & 1.7 \\
\hline \multicolumn{3}{|c|}{ Positive control group (1 $\left.\mathrm{mM} \mathrm{H}_{2} \mathrm{O}_{2}\right)$} & $35.4^{1}$ & 38.2 & 12.6 & $45.7^{1}$ & 30.2 & 26.1 \\
\hline
\end{tabular}

SD: Standard deviation.

${ }^{1}$ Statistically significantly different $(p<0.05)$ compared to the negative control.

${ }^{2}$ Statistically significantly different $(p<0.05)$ compared to the top surface $(0 \mathrm{~mm})$ of the same material at the same irradiation time. 
Table 3 - Results of micronucleus assay for lymphocytes treated with 48-h eluates of different composite materials in respect of irradiation time and layer depth.

\begin{tabular}{|c|c|c|c|c|c|}
\hline \multirow[t]{2}{*}{ Material } & \multirow[t]{2}{*}{$\begin{array}{l}\text { Irradiation } \\
\text { time (s) }\end{array}$} & \multirow[t]{2}{*}{$\begin{array}{l}\text { Depth } \\
(\mathrm{mm})\end{array}$} & \multicolumn{3}{|c|}{$\begin{array}{l}\text { Detected per } 1000 \text { cells } \\
(\text { mean } \pm \text { SD })\end{array}$} \\
\hline & & & Micronuclei & Nuclear buds & $\begin{array}{c}\text { Nucleoplasmic } \\
\text { bridges }\end{array}$ \\
\hline \multirow[t]{4}{*}{$\begin{array}{l}\text { SDR } \\
\text { S }\end{array}$} & 20 & 0 & $5.5 \pm 0.7$ & $8.5 \pm 0.7$ & $0.5 \pm 0.7$ \\
\hline & & 4 & $6.0 \pm 0.0$ & $6.0 \pm 1.4$ & $0.0 \pm 0.0$ \\
\hline & 30 & 0 & $7.0 \pm 0.0$ & $4.0 \pm 1.4$ & $0.0 \pm 0.0$ \\
\hline & & 4 & $7.0 \pm 1.4$ & $8.0 \pm 0.0$ & $0.0 \pm 0.0$ \\
\hline Venus & 20 & 0 & $7.5 \pm 0.7$ & $9.5 \pm 0.7$ & $0.5 \pm 0.7$ \\
\hline \multirow[t]{3}{*}{ Bulk Fill } & & 4 & $9.5 \pm 0.7$ & $10.0 \pm 0.0$ & $0.0 \pm 0.0$ \\
\hline & 30 & 0 & $5.5 \pm 0.7$ & $5.5 \pm 0.7$ & $0.0 \pm 0.0$ \\
\hline & & 4 & $7.0 \pm 0.0$ & $6.5 \pm 2.1$ & $0.0 \pm 0.0$ \\
\hline \multirow[t]{4}{*}{$x$-tra base } & 20 & 0 & $7.0 \pm 0.0$ & $10.0 \pm 1.4$ & $0.0 \pm 0.0$ \\
\hline & & 4 & $7.0 \pm 0.0$ & $8.5 \pm 0.7$ & $0.5 \pm 0.7$ \\
\hline & 30 & 0 & $8.0 \pm 1.4$ & $6.5 \pm 0.7$ & $0.0 \pm 0.0$ \\
\hline & & 4 & $7.0 \pm 1.4$ & $8.5 \pm 0.7$ & $0.0 \pm 0.0$ \\
\hline Tetric & 20 & 0 & $8.5 \pm 0.7$ & $9.0 \pm 0.0$ & $0.0 \pm 0.0$ \\
\hline \multirow[t]{3}{*}{ EvoFlow } & & 4 & $10.5 \pm 0.7$ & $15.5 \pm 0.7^{1}$ & $0.5 \pm 0.7$ \\
\hline & 30 & 0 & $8.5 \pm 0.7$ & $7.0 \pm 0.0$ & $0.0 \pm 0.0$ \\
\hline & & 4 & $10.0 \pm 1.4$ & $11.0 \pm 1.4$ & $0.0 \pm 0.0$ \\
\hline \multicolumn{3}{|c|}{ Negative control group (untreated) } & $6.5 \pm 0.7$ & $7.5 \pm 0.7$ & $0.0 \pm 0.0$ \\
\hline \multicolumn{3}{|c|}{ Positive control group (EMS $200 \mu \mathrm{g} / \mathrm{ml}$ ) } & $28.5 \pm 4.9^{1}$ & $23.5 \pm 2.1^{1}$ & $8.5 \pm 2.1$ \\
\hline
\end{tabular}

SD: Standard deviation.

${ }^{1}$ Statistically significantly different $(p<0.05)$ compared to the negative control. 
Table 4 - Mean ( \pm standard deviation) Knoop hardness $(\mathrm{KHN})$ of the composite materials at the top $(0 \mathrm{~mm})$ and bottom $(4 \mathrm{~mm})$ specimen surface $(\mathrm{n}=8)$.

\begin{tabular}{|c|c|c|c|}
\hline Material & Irradiation time (s) & Top surface & Bottom surface \\
\hline \multirow[t]{2}{*}{ SDR } & 20 & $35.4 \pm 2.2 \quad \mathrm{~B}, \mathrm{a}$ & $39.7 \pm 1.0 \quad$ A, a \\
\hline & 30 & $33.9 \pm 1.8 \quad \mathbf{B}, \mathbf{a}$ & $39.3 \pm 1.2 \quad \mathbf{A}, \mathbf{a}$ \\
\hline \multirow[t]{2}{*}{ Venus Bulk Fill } & 20 & $26.6 \pm 1.9$ A,a & $25.0 \pm 2.5 \quad \mathbf{A}, \mathbf{a}$ \\
\hline & 30 & $27.6 \pm 1.6 \quad \mathbf{A}, \mathbf{a}$ & $27.8 \pm 2.7 \quad \mathbf{A}, \mathbf{a}$ \\
\hline \multirow[t]{2}{*}{$x$-tra base } & 20 & $45.9 \pm 2.2 \quad$ A, $a$ & $42.9 \pm 3.9 \quad$ A, $a$ \\
\hline & 30 & $44.2 \pm 2.4 \quad$ A, $a$ & $42.1 \pm 1.7 \quad$ A, a \\
\hline \multirow[t]{2}{*}{ Tetric EvoFlow } & 20 & $32.9 \pm 1.3 \quad \mathbf{A}, \mathbf{a}$ & $23.5 \pm 1.3 \quad \mathbf{B}, \mathbf{b}$ \\
\hline & 30 & $31.1 \pm 1.4 \mathbf{A}, \mathbf{a}$ & $26.8 \pm 0.5 \quad B, a$ \\
\hline
\end{tabular}

Within each material, mean values followed by same capital letters in rows, and by same small letters in columns, are not significantly different at the 0.05 level. 